\title{
English-Chinese Translation of English and American Literary Works with Cultural Differences between China and the West
}

\author{
Liu Jia \\ School of English language and literature, Xi an FanYi University, Shaanxi, China, 710105
}

Keywords: cultural differences between China and the West; English and American literature; translation

Abstract: Due to the differences in geographical, customs and natural environment between China and the West, there are also great differences between Chinese and Western cultures, resulting in many difficulties in the translation of English and American literature. When translating English and American literature, people need to make a reasonable comparison between Chinese and Western cultures. They should not only take their own cultures as the starting point, but also have an effective understanding of Western cultural customs and cultural characteristics. They should also make a comparison between Chinese and Western cultures, pay attention to the differences between Chinese and Western cultures, and have a thorough understanding of Western culture and English and American literature in order to improve the quality of translation. The quality level of English and American literary translation. This paper mainly studies the influence of cultural differences on English and American literary translation, and through the analysis, seeks to improve the quality of English and American literary translation.

Different cultures lead to different aesthetic concepts. English-Chinese translation is the transmission of information between two cultures. Different nations have different cultures. These cultural differences will have a certain impact on our translation of English and American literary works. Therefore, when translating western literary works, we should not only study the western language, but also the social circle in which they are located. In this way, we can have a profound understanding of the ideological connotation expressed in western literary works.

\section{Specific Manifestations Of Cultural Differences Between China And The West}

\subsection{Differences In Religious Beliefs}

In the long history, the influence of religion on the development of the country and culture is very great. Therefore, in many literary works, we can see the shadow of religion. For western countries, the influence of Christianity is pervasive in all aspects of life. The Bible, as the classic of Christian religion, is the main carrier and carries the western culture. Compared with Western countries, there are three main religions in our country: Confucianism, Taoism and Buddhism. 
Buddhism is the most influential religion. It has penetrated into all aspects of life and has become an important manifestation of our culture. Therefore, when translating English and American literary works, we should pay special attention to the distinction between different religious cultures, so as to prevent translation errors due to religious cultures and affect the translation effect.

\subsection{Differences in Values and Cultural Customs}

Values refer to the value orientation of identifying things and judging right and wrong. Different values will have different understandings of the same thing. Western countries emphasize individual-centered and advocate individualism, while our country pays more attention to collective interests and emphasizes the overall situation. The differences in living environment and historical background lead to great differences in cultural customs between China and the West. For example, "dragon" symbolizes auspiciousness in our country, and we are also called the descendants of dragon, but in the Bible of Western countries, it is the symbol of devil and Satan. There are also some figures or words that are taboo between China and the West, such as Westernization on the number 13, while we are taboo on the number 4 and 7.

\section{Translation Skills of English and American Literary Works}

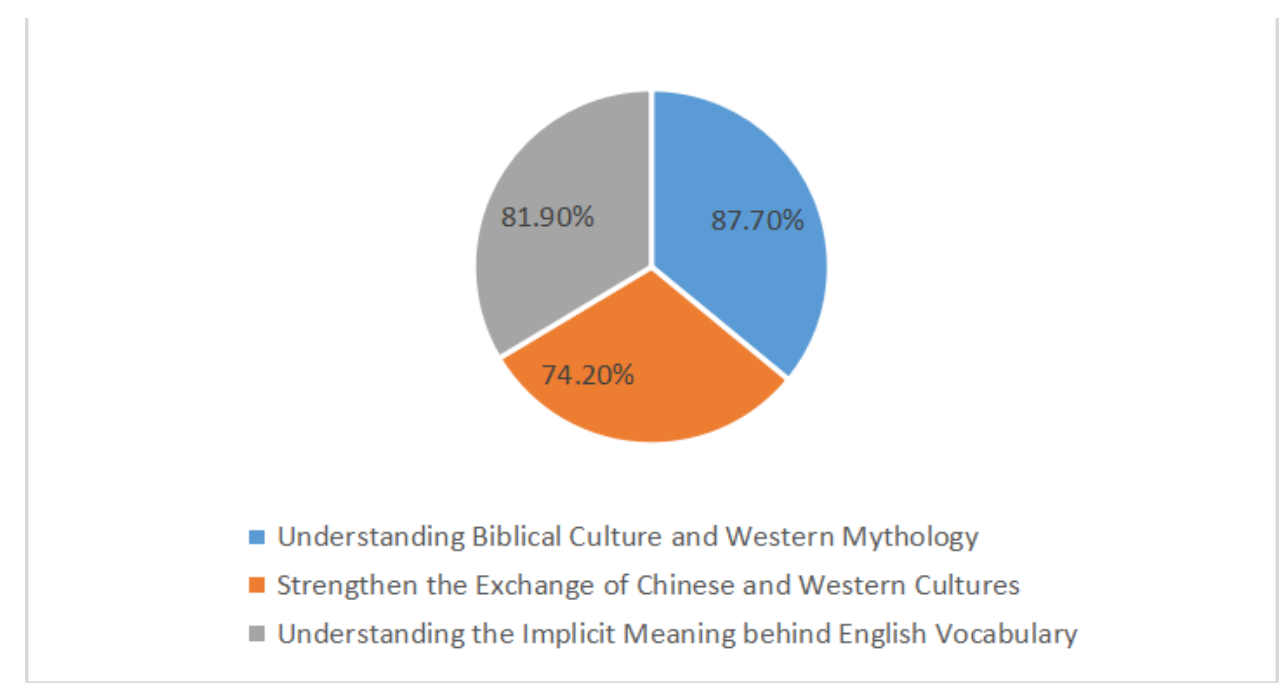

Figure1.Translation Skills

As shown in Figure 1, translation techniques are analyzed in detail below.

\subsection{Understanding Biblical Culture and Western Mythology}

In English and American literary works, there are often some Bible contents and some Western myths and stories. If we do not understand these contents thoroughly enough, we can not have a deeper understanding of the connotation of these literary works, nor can we fully grasp the profound meaning that the author wants to express, so we can only stagnate on the surface of the works when translating. Therefore, when translating English and American literary works, we need to have a comprehensive understanding of the Bible and Western myths, so as to better help us translate English and American literature more accurately.

\subsection{Strengthen the Exchange of Chinese and Western Cultures}

Generally speaking, before carrying out translation work, we will read a large number of 
documents to understand the history and culture of Western countries. Today, with the rapid development of the Internet, we can also use the Internet to find the film and television materials of western countries to have a deeper understanding of British and American literary works. In addition, qualified translators can also choose to make on-site investigations of the localities of English and American literary works, experience the local living environment and customs, deeply understand the cultural differences between China and the West, and familiarize themselves with the historical background of western literary works. Only by combining the works with culture can literary works with profound cultural connotations be translated.

\subsection{Understanding the Implicit Meaning behind English Vocabulary}

When translating English and American literature, we should combine context with translation. We should not only look at the superficial meaning, but also bring cultural differences into it. Previously, literal translation was mostly used in the translation of English and American literary works in China, that is, to translate the superficial meaning without thinking deeply about its inherent meaning. With the rapid development of our society, we have a deeper understanding of the application of English and more flexible use of English idioms. For example, smell a rat is literally used by ordinary people. Meaning translation is to smell a rat, so the translation is obviously incorrect. The correct meaning should be to feel bad about something. Generally speaking, the meaning of English idioms is formed through long-term cultural accumulation and precipitation. Therefore, when we translate, we should not only look at the superficial meaning, but also combine Western culture and specific context.

\section{Measures to Reduce the Impact of Cultural Differences between China and the West on English-American Literature Translation}

In the translation of English and American literature, the differences between Chinese and Western cultures have a great influence on it. Therefore, in order to translate English and American literature accurately, we need to face the cultural differences between different regions, interpret the western culture in detail, and lay a solid foundation for the translation of English and American literature accurately. As shown in Figure 2.
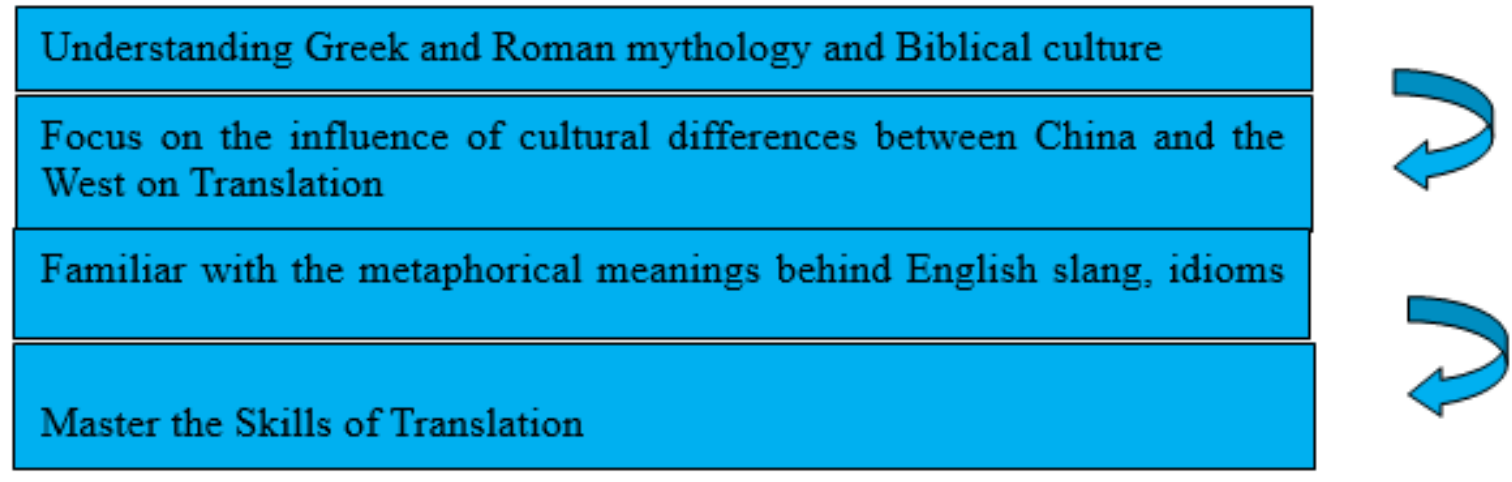

Figure 2.Measures to Reduce the Impact of Cultural Differences between China and the West on English-American Literature Translation

\subsection{Understanding Greek and Roman mythology and Biblical culture}

In British and American literature, the contents of Greek and Roman mythology and Bible culture are often infiltrated, which have a great influence. And the prosperity of British and 
American literature is a period of social turbulence. So people at that time placed their hopes in Greek and Roman mythology and Bible culture. Therefore, most of the English and American literary works will draw lessons from one another when they draw materials. Some of the myths and the Bible are inspired by them when they are written. Therefore, when translating English and American literary works, it is necessary to have a comprehensive understanding of Greek and Roman mythology and Bible culture. If we have a one-sided understanding, we may not understand some allusions in the works or the contents related to religious culture. It is difficult for the translated works to express the author's ideas or disseminate the values in the works.

\subsection{Focus on the influence of cultural differences between China and the West on Translation}

With the rapid development of modern society and economy, translators usually look for a large number of documents before carrying out translation activities. They can understand the differences between Chinese and Western cultures through books. In order to fully understand the differences between Chinese and Western cultures, it is necessary to expand cultural information from various angles and from various aspects, and to improve cultural communication ability by broadening channels. And in the actual translation preparation work, we need to fully play the role of the network, the modern network knowledge system has gradually improved with the progress of the times, so translators can use the network to search articles and movies and so on, in order to strengthen the perceptual understanding of Anglo-American literature.

\subsection{Familiar with the metaphorical meanings behind English slang, idioms and vocabulary}

Among the cultural exchanges among countries, translation is one of the most effective ways to promote cultural communication among regions. It can not only promote cultural exchanges and integration, but also effectively promote regional economic development. Therefore, in the process of translation, it is necessary to combine specific contexts and incorporate cultural differences into the transformation between language and text. With the development of modern society, the application of English in our country is also deepening. Therefore, the use of slang and idioms in English is becoming more flexible. The emergence of such words as Milky Way will be translated literally into Milky Way, but people will also feel that the application of slang and idioms in articles is very abrupt. The slang and idioms in general English have fixed meanings.

\subsection{Master the Skills of Translation}

The main purpose of translation is to translate the two languages reasonably, which can also be called the process of trading and decoding. Therefore, when translating, we need to increase or decrease the number of words appropriately, and constantly adjust the order of sentences. When translating, the translator sums up the meaning of words in the text into the cultural category of the translated language and applies the same meanings to the translation, which is the domestication strategy. The domestication strategy is mainly embodied in the "equivalence" between cultures of different countries. After translation, translators make their texts easy to understand. When reading, readers can understand foreign literary works without too much knowledge. 


\section{Conclusion}

This paper mainly studies the influence of cultural differences on the translation of English and American literature. Since the translation of English and American literature is the basis of promoting cultural exchanges between countries and can effectively promote language exchanges between different countries, translators need to pay attention to language problems and integrate the differences between Chinese and Western cultures into their translation work. When carrying out the actual translation work, we can't directly translate the text, otherwise we can't express the connotation of literary works. Therefore, translators need to fully understand the Chinese and Western cultures and try their best to ensure the "taste" of the translated articles. And translation itself is one of the cultural learning tasks, so we need to take culture into full consideration in language conversion. Differences.

\section{Acknowledgements}

Name of the Fund: 1) Moocs Construction for Basic English Subject

2) English Language Service and Regional Economic Cooperation Development Research Team Serial Number: XFU17KYTDC09

\section{References}

[1] Chen Angelia. On the Importance of Emphasizing Cultural Differences in English-Chinese Translation [J]. Journal of An yang Normal University, 2008, (6).

[2] Sun Kaifeng. Reflections of Cultural Differences in English-Chinese Translation and Translation Methods [J]. China Science and Education Innovation Guide, 2007, (12).

[3] Han Li. Cultural Differences between China and the West and English-Chinese Translation of English and American Literature [J]. Mange, 2013, (15).

[4] Tang Kaifeng. Main manifestations of cultural differences in business English translation and their solutions [J]. Journal of Changchun University of Technology, 2012, (6).

[5] Bin Jun. Cultural Differences between China and the West and English-Chinese Translation Studies of British and American Literature J. Journal of Ginsu Union University: Social Science Edition, 2009, (5). 